\title{
O DESAFIO DA ACESSIBILIDADE: UM CASO DE PESQUISA-AÇÃO NO CURSO DE PEDAGOGIA A DISTÂNCIA DO CONSÓRCIO CEDERJ/UERJ
}

Alice Maria Reis Costa | alicemaria.costa@yahoo.com.br

Pedagoga pela UERJ, pós-graduada latu sensu em Psicopedagogia pela UERJ e em Educação Especial pela UNIRIO. Exerce tutoria presencial pela Fundação Cecierj/UERJ nas disciplinas Informática na Educação no Curso de Pedagogia e Introdução à Informática nos Cursos de Licenciatura. Atua em tutoria a distância pela Fiocruz no curso Teoria e Prática dos Conselhos Tutelares e de Direitos da Criança e do Adolescente. Suas pesquisas têm focalizado os temas inclusão social/digital, tecnologia e educação e metacognição.

\section{Resumo}

Este artigo apresenta propostas de mediação pedagógica a partir da tutoria presencial realizada na disciplina Informática na Educação da graduação em Pedagogia, visando à inclusão de pessoas com necessidades educacionais especiais (NEE) no contexto da Fundação Cecierj.

\section{Palavras-chave}

Tecnologias assistivas. Acessibilidade. Informática na Educação Especial.

\section{THE CHALLENGE OF ACCESSIBILITY: A CASE FOR RESEARCH AND ACTION IN THE ONLINE COURSE OF PEDAGOGY AT THE CEDERJ CONSORTIUM/UERJ}

\author{
Abstract: \\ This paper presents proposals of a pedagogical \\ mediation from the face-to-face tutoring conduc- \\ ted in the discipline of IT in Education for the \\ Bachelor degree in Pedagogy, aiming at the inclu- \\ sion of people with special educational needs in \\ the context of the Cecierj Foundation. \\ Keywords: Assistive technologies. Accessibility. \\ IT in Special Education. Computers in Special \\ Education.
}

\section{Introdução}

A partir do desafio de democratizar o acesso ao ensino superior e seguindo as diretrizes do Plano Nacional de Educação, o propósito deste artigo é discutir e apresentar propostas de mediação pe- dagógica visando à inclusão de alunos com necessidades educacionais especiais. Como estudo de caso para nossa análise, realizamos o acompanhamento pedagógico no decorrer do primeiro semestre de 2010 junto a uma aluna deficiente visual que iniciou o curso de graduação em Pedagogia em 2007 pela Fundação Cecierj/Consórcio Cederj nas tutorias presenciais da disciplina Informática na Educação.

Faz-se necessário esclarecer que

incluir significa organizar e implementar respostas educativas que facultem a apropriação do saber, do saber fazer e da capacidade crítica e reflexiva; envolve a remoção de barreiras arquitetônicas, sim, mas sobretudo das barreiras atitudinais - aquelas referentes ao "olhar" das pessoas normais e desinformadas - para que se promova a adequação do espaço psicológico que será compartilhado por pessoas muito diferentes entre si (CARVALHO, 1999 apud SIQUEIRA \& SANTANA, 2010, p. 128). 
Em seu papel de transformação social, compete à universidade contribuir na busca da do acesso ao seu alunado, seja com adaptações físicas em sua estrutura funcional, ou com a utilização de hardwares ou de softwares especiais de acessibilidade. Para efetivamente desencadear o processo de inclusão, as novas tecnologias da informação e comunicação anunciam provocar uma nova transformação (SANTAROSA, 2002, p. 532).

\section{Observações sobre a aluna M}

O contexto universitário possui sua própria "cultura, tal como está configurada, reconhecida e valorizada" (CANDAU, 2006), permitindo a inserção de novos atores no seu mundo. Dentro desse contexto, sob a perspectiva do multiculturalismo, McLaren (1997) entende que haja um "pré-requisito para juntar-se à turma, desnundar-se, desracializar-se e despir-se de sua própria cultura" (CANDAU, 2006 apud MCLAREN, 1997, p. 42).

Nesse propósito, a equipe do Cederj envolvida nas tutorias presenciais e a distância se aproximou dessa aluna, que nos contou um pouco de sua história de vida. Chamá-la-emos $\mathrm{M}$ com a intenção de preservar a sua identidade.

Conhecer a trajetória de $\mathrm{M}$ no universo acadêmico nos traz outras implicações, como conhecer as redes, os contextos que ela, na sua história de vida, trouxe para a rede acadêmica do Polo $\mathrm{Ce}$ derj Angra dos Reis. Concordo com Elias (1994), quando diz que "para se compreender alguém é preciso conhecer seus anseios e seus desejos. São esses que vão determinar o sentido da vida de um indivíduo" (CAPUTO, 2001 apud ELIAS, 1994, p. 6).

M nasceu com baixa visão devido à alta miopia degenerativa, ocasionando a perda da visão total do olho direito aos 16 anos de idade. Submeteu-se a duas cirurgias médicas: a primeira com 24 anos de idade, uma operação de catarata precoce desenvolvida por um traumatismo, conforme seu relato sobre as informações médicas, e nesta foi detectado um deslocamento total de retina; e a segunda ocorreu quinze anos mais tarde, quando da retirada do olho direito e a colocação de uma prótese.

Nesse período cursou o Ensino Fundamental (antigo $1^{\circ}$ grau) vestindo óculos com alto grau, aproximadamente 27; nos anos 1980, parou de estudar por recomendações médicas, para não forçar a visão, mas depois de vinte anos, após ter casado e criado seus filhos, decidiu que voltaria a estudar, optando por um curso de Formação de Professores, antigo curso Normal, em horário diurno, porque achava que dessa forma não iria forçar muito a vista; na $1^{\text {a }}$ série conseguiu ler e escrever, com algumas dificuldades para enxergar o que estava escrito no quadro. Passou para a $2^{\mathrm{a}}$ série do Ensino Médio, quando conheceu a Escola Municipal para Deficientes Visuais/Centro de Apoio Pedagógico (CAP), destinado ao acompanhamento escolar de cegos, surdos-cegos, de baixa visão e múltiplas deficiências, localizada no município de Angra dos Reis. Ali começou a aprender o sistema de leitura para cegos, o Sistema Braille ; nessa escola seus textos foram ampliados, enquanto em paralelo estudava o código universal de leitura e de escrita tátil.

Em setembro de 2004, durante a Olimpíada da Pessoa Deficiente (Olimpede), realizada em Volta Redonda (RJ), sentiu uma brusca perda da visão e logo após foi para uma consulta no Instituto Benjamin Constant (IBC), na qual recebeu o encaminhamento para aprender a utilizar outros recursos que a ajudariam a lidar com as novas situações de orientação que daquele momento em diante necessitaria. Dessa forma, amigos ledores e o pessoal da E. M. para Deficientes Visuais/CAP ajudaram com o apoio pedagógico e lendo as provas até a conclusão do Ensino Médio no ano de 2005.

Em 2006, com incentivo de seu filho, resolveu prestar o vestibular Cederj para acesso à universidade, optando pelo curso de Pedagogia para dar continuidade à Formação de Professores; foi aprovada em $13^{\circ}$ lugar para vaga de ampla concorrência, pois havia passado o período de inscrição por cotas . Mesmo assim a prova foi mediada por um ledor da Fundação Cecierj. 
No início da graduação, não teve material adaptado para estudar; assim, por meio de uma ação conjunta mediada pela direção do Polo Cederj Angra dos Reis, conseguiu apoio do CAP e de ledores voluntários para ler o material impresso; na disciplina Introdução à Informática, existente no $1^{\circ}$ período, contou que foi reprovada porque não havia tutoria especial nem material adaptado. Disse que, no $2^{\circ}$ período, a Fundação Cecierj possibilitou a instalação do Sistema Operacional DOSVOX (de que falarei adiante) em um dos computadores do Laboratório de Informática, mas sem tutoria especializada. Com isso, não obteve êxito no aprendizado prático, pois "decorei as instruções das apostilas, o que me proporcionou a aprovação" (sic).

$\mathrm{M}$ recordou que "entre os $2^{\circ}$ e $3^{\circ}$ períodos uma equipe do Cederj dos setores Plataforma e Material Impresso, entre outros vieram me conhecer para ver o que poderia ser feito para ajudar; a partir daí, descartamos o material impresso em Braille, devido ao volume e ao tempo para a transcrição, além da minha falta de domínio da escrita Braille" (sic); Decidiram, em conjunto com M, que o material seria fornecido em áudio por meio de CD-ROM. M acrescentou: "no início participei das revisões para aperfeiçoar a qualidade do material que passou a ser fornecido, e as provas eram feitas com a ajuda dos tutores ledores" (sic).

$M$ recordou que usou material em Thermoform ou cópia impressa em plástico quente, além do Material Concreto (figuras geométricas) para possibilitar o aprendizado de forma concreta para a disciplina Matemática na Educação.

$\mathrm{O}$ ingresso de $\mathrm{M}$ no ensino superior no curso de Pedagogia para as Séries Iniciais trouxe para a equipe do Cederj uma série de questões: como adaptar o material didático de forma que ela possa estudar? Como mediar as tutorias presenciais? Como mediar as tutorias a distância? Como garantir a igualdade de condições para realização das avaliações a distância (ADs) e presenciais (APs)? Quais as adaptações curriculares necessárias para garantir seu bom desempenho? Como capacitar os professores tutores em tempo hábil para trabalhar com a aluna?

Essas e outras questões foram surgindo ao longo de nossos dias, assim como as soluções e mediações possíveis no contexto universitário de um curso a distância. Para Alves (2008),

trabalhar com o cotidiano e se preocupar como aí se tecem em redes os conhecimentos significa, ao contrário, escolher entre as várias teorias à disposição e muitas vezes usar várias, bem como entendê-las não como apoio e verdade, mas como limites, pois permitem ir só até um ponto, que não foi atingido, até aqui pelo menos, afirmando a criatividade no cotidiano (ALVES, 2008, p. 24).

Diante de tantas conversas e reflexões para tornar efetiva a possibilidade de inclusão, a própria equipe foi encontrando algumas soluções; por exemplo, foi destinada uma professora-tutora-mediadora-presencial para acompanhar o desenvolvimento da aluna em todas as disciplinas, além de um ledor para realização das avaliações presenciais; desse modo, a metodologia do início de uma pesquisa-formação foi se desenhando dia a dia.

\section{Tutor: professor-tutor-pesquisador}

Chegado o período em que a equipe de coordenação do curso de Pedagogia considerou possível para o estudo da disciplina Informática na Educação, após o mapeamento dos avanços e dificuldades encontradas no decorrer da vida acadêmica de $\mathrm{M}$, fomos à busca de softwares e hardwares que proporcionassem maior autonomia à aluna.

Esse período de nossas investigações foi muito rico porque, na condição de professores-tutores-pesquisadores, podemos refletir e repensar a própria prática docente cocriando etnométodos, nossos "métodos próprios para lidar com as situações educacionais, aprendendo com o dia a dia da comunidade acadêmica" (SANTOS, 2007) em relação ao fazer pedagógico; podemos apontar possibilidades de construção de Tecnologias Assistivas (TA) ou Ajudas Técnicas (AT), no que concerne a hardwares e softwares para facilitar $e$ 
viabilizar a aprendizagem em cursos de graduação a distância.

Santos (2007) diz que:

pesquisador não é aquele que constata o que ocorre, mas aquele que intervém como sujeito de ocorrências. Ser sujeito de ocorrências no contexto de pesquisa e prática pedagógica implica conceber a pesquisa-formação como processo de produção de conhecimentos sobre problemas vividos pelo sujeito em sua ação docente. (...) A pesquisa-formação não dicotomiza a ação de conhecer da ação de atuar. (...) O pesquisador é coletivo, não se limita a aplicar saberes existentes, as estratégias de aprendizagem e os saberes emergem da troca e da partilha de sentidos de todos envolvidos (SANTOS, 2007, p. 13-14).

Para se apropriar desse trabalho, os professores tutores investigaram o ambiente virtual de aprendizagem do Cederj, chamado Plataforma Cederj, com o objetivo de identificar as facilidades e dificuldades para a pessoa com necessidades educacionais especiais, prioritariamente no que concerne à deficiência visual. Da mesma forma, tomamos conhecimento de outros ambientes virtuais acessíveis, como a plataforma Interagir (www.interagir.uff.br), resultado de uma parceria do Grupo de Inclusão Digital do Instituto de Computação da Universidade Federal Fluminense (UFF), localizada no município de Niterói, com o Instituto Benjamin Constant (IBC), no Rio de Janeiro.

Com os estudos de Lázaro (2005), aprendemos mais um pouco sobre a deficiência visual ; ele afirma:

O deficiente visual pode ser educacionalmente cego ou com baixa visão.

É considerado cego aquele que apresenta desde ausência total de visão até a perda da percepção luminosa. Sua aprendizagem se dará através da integração dos sentidos remanescentes preservados. Terá como principal meio de leitura e escrita o sistema Braille. Deverá, no entanto, ser incentivado a usar seu resíduo visual nas atividades de vida diária, sempre que possível.

É considerado com baixa visão aquele que apresenta desde a capacidade de perceber luminosidade até o grau em que a deficiência visual interfira ou limite seu desempenho. Sua aprendizagem se dará através dos meios visuais, mesmo que sejam necessários recursos especiais. As patologias que levam à deficiência visual incluem, principalmente, alterações das seguintes funções visuais: visão central, visão periférica e sensibilidade aos contrastes.

A equipe da disciplina Informática na Educação foi contemplada com o acréscimo de duas horas de tutoria especial para mediar o processo de ensino e aprendizagem de $\mathrm{M}$ durante o período 2010/1. Ela ocorreu fundamentada na perspectiva de que a aprendizagem e o desenvolvimento do ser humano ocorrem a partir de suas interações com o meio e com os outros, sendo assim desde a infância, ou seja, a sustentabilidade desse trabalho se deu segundo a teoria sociointeracionista de Vygotsky (1998).

Com base nos estudos de Vygotsky (1998), foram desenvolvidos três conceitos importantes para a compreensão do processo de ensino e aprendizagem: o primeiro se refere ao conhecimento que já é de domínio do indivíduo, identificado no nível de desenvolvimento real; o segundo é o nível de desenvolvimento potencial, em que estão as coisas que uma pessoa pode fazer com a colaboração e cooperação de outras pessoas; a partir dessa distância entre o nível de desenvolvimento real e o nível de desenvolvimento potencial ele desenvolveu o conceito de zona de desenvolvimento proximal.

A zona de desenvolvimento proximal da criança é a distância entre seu desenvolvimento real, que se costuma determinar mediante a solução independente de problemas e o nível de seu desenvolvimento potencial, determinado pela solução de problemas sob a orientação de um adulto ou em colaboração com companheiros mais capazes (VYGOTSKY, 1998, p. 112).

Sobre isso, Góes (1991, p. 20) acrescenta: "a boa aprendizagem é aquela que consolida e, sobretudo, cria zonas de desenvolvimento proximal sucessivas"; para enriquecer essas mediações, oriundas não só de seus pares mas também do ambiente físico e virtual desses encontros e de- 
sencontros, contamos com os avanços das tecnologias da informação e comunicação (TICs). Para Garcia (2001), "o mundo da educação não pode ignorar essa realidade tecnológica como objeto de estudo e, muito menos, como instrumento para a formação de cidadãos que já se organizam nessa sociedade através de ambientes virtuais" (GARCIA, 2001, p. 161).

Os diferentes ambientes virtuais de aprendizagens evoluem de alguns nós, aparentemente isolados e pequenos que se entremeiam em tantos outros, tecendo uma imensa rede de conhecimento entre meados do século XX e a primeira metade do século XXI. A compreensão do espaço-tempo de Harvey (1992) e do desencaixe de Giddens (1991) fazem o homem se repensar e refazer a cada instante, num ritmo de tempo e espaço peculiares de uma nova época. Isso representa um salto para o futuro na descoberta diária de novos modos de aprender, fazer, construir e se construir nas relações humanas e destas com a tecnologia.

Sobre essa resignificação da tecnologia na vida humana, Parente (2004) infere:

até agora, as novas tecnologias resultaram em um processo de estranha mistura de enriquecimento e empobrecimento, singularização e massificação, desterritorialização e reterritorialização, potencialização e despotencialização da subjetividade em sua dimensão autorreferencial (singularizante, processual, dissensual) (p. 93).

Nesta chamada "era digital", Santaella (2004, p. 11) considera que as "linguagens sonoras, visuais, verbais e do emaranhado de suas misturas" se estabelecem ressignificando conceitos de linguagem e comunicação que, potencializados pelas hipermídias, tornam inevitável que novas formas de aprender a aprender vão se configurando em nosso cotidiano.

A aprendizagem no ciberespaço implica outra postura daquele que ensina e daquele que aprende; nessa perspectiva, ambos produzem conhecimento, mediante uma postura ativa que incentiva a elaboração de estratégias voltadas para a solução de problemas, ou seja, a lógica comunicacio- nal todos-todos é outra.

Freire (1987) reconhece a capacidade do ser humano de criar e recriar o conhecimento sobre o cotidiano que o envolve e possibilita a sua transformação social, econômica, emocional, cognitiva a partir de conhecimentos produzidos no coletivo; com isso, o ser humano busca dar sentido ao mundo em que vive.

Conhecimento... Necessita a presença curiosa de sujeitos confrontados com o mundo. Requer sua ação transformadora sobre a realidade. Demanda uma constante busca... No processo de aprendizagem, a única pessoa que realmente aprende é aquela que... re-inventa o que aprende (FREIRE, 1987, p. 101).

\section{Sobre a metodologia de pesquisa}

Foram feitas algumas gravações durante a tutoria, a fim de não perder dados que poderiam facilitar a identificação das necessidades de M. As gravações apresentam um enquadramento para o usuário e o fundo que revela o ambiente do Laboratório de Informática perdendo a trajetória percorrida por $\mathrm{M}$ ao mexer no computador e navegar no ciberespaço, devido ao fato de a câmera do notebook ser fixa e não ter sido possível utilizar a câmera externa, fato este que furtou nossa mobilidade de capturar outros ângulos, principalmente a navegação de $\mathrm{M}$; contudo, conseguiu-se obter as conversas que se davam em momento de tutoria, revelando a mediação pedagógica $e$ os avanços e limitações conseguidas no semestre letivo com a aluna.

Nesse período me questionei muito em relação ao vivido e sobre o caminho mais adequado para conduzir este processo de ensino e aprendizagem. Apesar de alguns debates com colegas tutores da área da computação e no próprio Grupo de Pesquisa Docência na Cibercultura (GPDOC), sentia falta de conhecimento que me fornecesse os instrumentos necessários para compreender e "interpretar" o vivido durante as tutorias.

Nesse sentido, procedeu-se a uma busca sobre metodologia de pesquisa, em estudiosos do as- 
sunto, como Moura (2005), no que concerne à sistematização da observação e entrevista; Macedo (2006), que traz a importância da mediação do pesquisador que precisa estar ciente das influências de sua atuação, mostrando "as inteligibilidades do senso comum e com elas constrói sua compreensão" e sofre influência do encontro cotidiano com seu objeto de estudo, por meio da interação com outras pessoas imersas na realidade de um curso de graduação a distância.

Nessa relação complexa da vida cotidiana (MORIN, 1990) permeada de "regularidades, contradições, paradoxos, ambiguidades, ambivalências, assincronias, insuficiências, transgressões, traições, etc.", conforme revela Macedo (2006, p. 14) o professor-tutor-pesquisador se percebe implicado no "ato eminentemente político de educar". Nessa relação vai simultaneamente se alterando e se autorizando com os fundamentos filosóficos, sociológicos e pedagógicos que lhe são possíveis no momento, a fim de significar e ressignificar suas próprias ações.

Barbier (2007) afirma que "as noções entrecruzadas podem ser concebidas como meios praxiológicos para compreender o que une pesquisa e ação na nossa problemática" (BARBIER, 2007, p. 86).

As construções que foram possíveis se atribuem ao fato de que as trocas $e$ as curiosidades eram compartilhadas no coletivo do grupo de alunos que frequentavam a tutoria presencial, principalmente entre a professora-tutora-pesquisadora e a graduanda. Assim foi se descobrindo certa autonomia-dependente, como diz Morin (1990): "ser sujeito é ser autônomo, ao mesmo tempo que dependente. É ser alguém provisório, vacilante, inseguro; é ser quase tudo para si e quase nada para o universo" (MORIN, 1990, p. 89).

Por pouco entender de todas essas teorias que atravessam a minha leitura e prática cotidiana, permitindo-me o lugar das incertezas que me levou a buscar na Sociologia a possibilidade de não enquadrar, recortar em demasiado o lugar de onde olho, considerando que

"tudo serve" para a Sociologia, tudo é método, tudo "encaminha". Nesse sentido, a experiência, seja ela qual for, encerra uma potencialidade cognitiva. A demarcação pode ser uma noção peculiar à política, à moral ou a certa forma de ciência - mas não serve, de modo algum, para a definição do conhecimento (MAFFESOLI, 2010, p. 199).

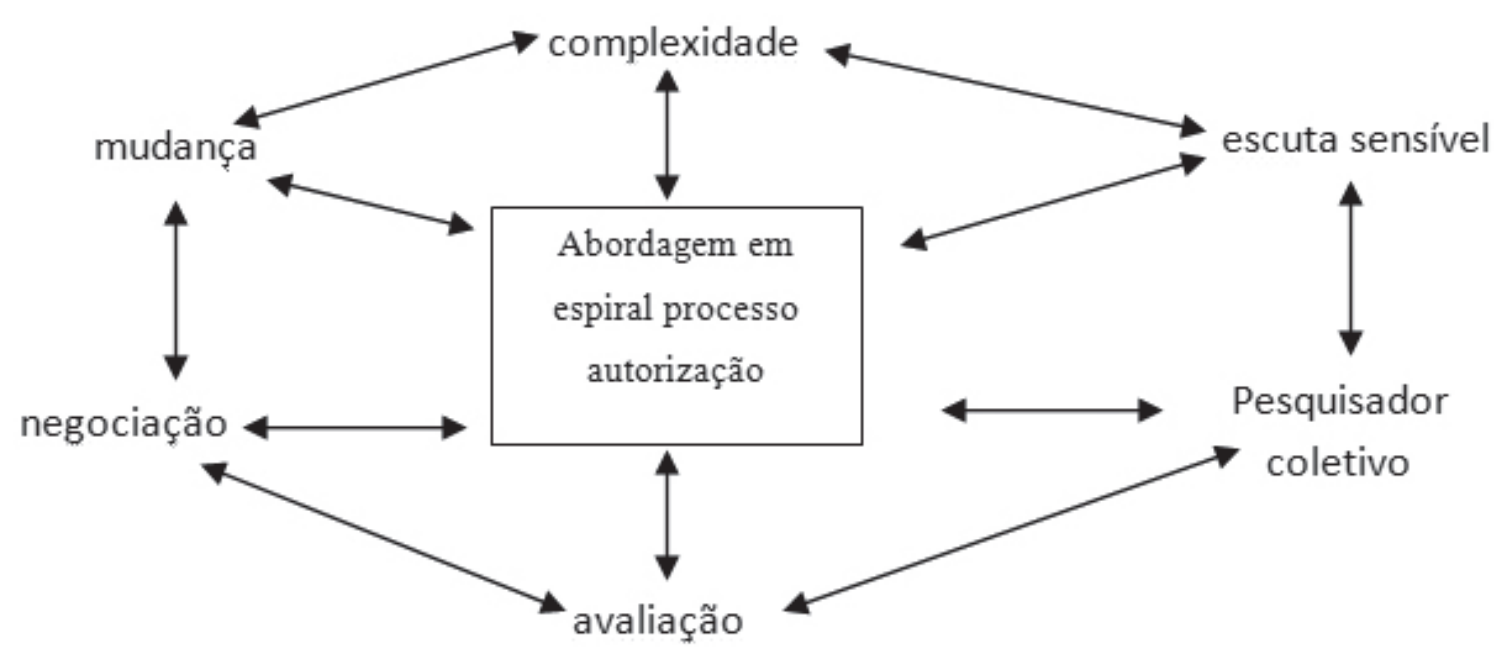

Figura 1: As noções entrecruzadas em pesquisa-ação

Fonte: Barbier (2007, p. 86). 
Nessa relação dialógica podemos vivenciar situações diferenciadas de ensino e aprendizagem com M nas tutorias presenciais da disciplina Informática na Educação. Outras questões foram se constituindo e sendo reconstruídas. Quais técnicas de ajuda poderiam servir efetivamente para mediar a aprendizagem da aluna que já trazia um relato de frustrações no que concerne à interatividade com o computador? Como proporcionar o acesso à Plataforma Cederj para a participação em fóruns? Como visualizar e analisar blogs educativos existentes no ciberespaço com e para uma aluna com deficiência visual? Como uma futura professora com deficiência visual poderia construir um blog? Enfim, como o digital considerado estruturante de novas modalidades comunicacionais pode contribuir no campo do currículo e da Educação Especial?

\section{Mídias móveis}

$\mathrm{O}$ uso de notebook, pen drive, CD-ROM, celular (ligações e torpedos via Serviço de Mensagens Curtas - SMS) possibilitaram a interação e a interatividade aluno-computador-tutor; assim foi possível agendar encontros mais flexíveis para a realização da tutoria, buscar e fornecer orientações de como modificar o plano de fundo do blog, inserir gadget de seguidores, postar fotos entre outros assuntos inerentes à disciplina. Nesse contexto permeado pela mobilidade, fazemos referência a Lemos (2009) quando considera a importância da acessibilidade e a adoção do comum como pré-requisitos para a inclusão integral:

A acessibilidade e a adoção do comum (o commons, tão usurpado pelos poderes privados) são elementos vitais nas tênues práticas associadas à tecnologia móvel, que, exatamente por esse viés, talvez as tornem menos um novo gadget de mediação e talvez mais uma ferramenta de aproximação da realidade social - ou, ainda, uma forma de contato entre realidades sociais que permaneceriam, de outra forma, talvez distantes (LEMOS, 2009, p. 119).

\section{Novos campos semânticos na Pedagogia}

Para os profissionais da Educação, a investida desafiadora em tornar ambientes físicos e virtuais acessíveis pode causar estranheza, considerando que termos como hardware, softwares, usabilidade, acessibilidade, tecnologias assistivas etc. ainda não fazem parte de seu repertório tecnológico.

Comumente nos lançamos a executar tarefas simultâneas que requerem o uso de vários sentidos de nosso corpo; por exemplo, imagine você que atualmente crianças, adolescentes e adultos jogam um game enquanto navegam na internet, batem papo pelo MSN e ainda comem em frente ao computador. Você já pensou em realizar essas tantas tarefas sem algum de seus sentidos? Ou mesmo você se adaptou a realizar essas tarefas sem usufruir todos os seus sentidos? Pode ser também que você nem consiga executar essas tarefas ainda por necessitar de adaptações que permitam alguma mobilidade, interatividade etc.

Sabemos que cada sujeito é dotado de competências e habilidades que devem ser consideradas de forma isolada e em seu conjunto para a execução de qualquer tarefa em ambientes diversificados. Para a navegação no ciberespaço não é diferente; ela não implica linearidade para realizar alguma ação.

Nesse sentido foram desenvolvidos pela Equipe Acessibilidade Brasil os seguintes pressupostos do conceito de desenho universal:

- Equiparação nas possibilidades de uso;

- Flexibilidade no uso;

- Uso Simples e intuitivo;

- Captação da informação;

- Tolerância ao erro;

- Mínimo esforço físico;

- Dimensão e espaço para uso e interação.

Ao trabalhar com $\mathrm{M}$ nas tutorias presenciais, percebi que pensar no desenvolvimento de uma interface de uso educacional implica incorporar os desejos dos sujeitos usuários a fim de facilitar o aprendizado e perceber que o deficiente visual terá que mapear um caminho para participar do fórum pelo som emitido. Mas se sua ferramenta não dis- 
põe de um kit multimídia, como poderá interagir $\mathrm{com} /$ na interface do AVA?

Chamamos de interface a porção visível para o usuário de um software, programa ou aplicativo; é pela interface que ele irá interagir; portanto, a interface deve ser qualificada de acordo com o ponto de vista do usuário. Esse foi o trabalho iniciado na transcrição das aulas (textos) em áudios gravados em CD-ROM para M estudar em seu curso de graduação pela Fundação Cecierj.

Para orientar $\mathrm{M}$ no acesso à Plataforma Cederj utilizando o software leitor de telas e textos, NVDA, recorri à verificação de alguns atributos revelados nos estudos de Nielsen (1993) sobre consistência e flexibilidade, referindo-se

a tarefas que requerem uma sequência de processos similares, que levam a supor que tenham efeitos similares, assim como entrar numa página de hierarquia inferior me leva a supor que terá uma sequência de links semelhantes à sua "página-mãe" ou, pelo menos, à imediatamente anterior. Flexibilidade refere-se à variedade de formas com que um usuário consegue atingir um mesmo objetivo (NIELSEN, 1993, p. 26).

Nesse sentido, passei de forma simples, direta $e$ o mais objetiva possível as orientações no ciberespaço que deveriam conduzir $M$ à realização das tarefas propostas na disciplina, com o intuito de provocar a "usabilidade" em uma interface que ultrapassa a minha mediação na condição de tutora. Por isso, buscar soluções em outros programas proporcionou uma amostra do que deve se concretizar em um AVA pensado a partir desses atributos e pressupostos de "acessibilidade". Para Godinho (2001) isso implica três noções:

'usuários', 'situação' e 'ambiente': o termo "usuários” significa que nenhum obstáculo deverá ser imposto ao indivíduo face às suas capacidades sensoriais e funcionais. O termo 'situação' significa que o sistema é acessível e utilizável em diversas situações, independentemente do software, comunicações ou equipamentos; o termo 'Ambiente' significa que o acesso não é condicionado pelo ambiente físico envolvente, exterior ou interior (GODINHO apud RODRIGUES, 2001).
Antes de desenvolver páginas para web, devem ser avaliadas situações e características diversas, como incapacidade de ver, ouvir ou deslocar-se; dificuldade visual para ler ou compreender textos; incapacidade para usar o teclado ou o mouse; insuficiência de quadros, apresentando apenas texto ou dimensões reduzidas; dificuldade para falar ou compreender; ocupação dos olhos, ouvidos ou mão e desatualização (pelo uso de navegador com versão muito antiga); esses fatores devem promover a reflexão em um projeto dessa natureza. Com esse foco, faz-se necessário aprofundar as recomendações do World Wide Web Consortion (W3C, consórcio para a web) e da Web Accessibility Initiative (WAI, Iniciativa para a Acessibilidade na Rede) .

À luz dessas perspectivas, a Plataforma Cederj foi estudada e sobre essa breve análise, que não teve a pretensão de esgotar o assunto, se inferiu que esse ambiente virtual de aprendizagem necessita ser reestruturado segundo as indicações da W3C e WAI.

A deliberação do Comitê de Ajudas Técnicas da Coordenadoria Nacional para Integração da Pessoa Portadora de Deficiência (Corde) sobre tecnologia assistiva definiu que

tecnologia assistiva é uma área do conhecimento, de característica interdisciplinar, que engloba produtos, recursos, metodologias, estratégias, práticas e serviços que objetivam promover a funcionalidade relacionada à atividade e à participação de pessoas com deficiência, incapacidades ou mobilidade reduzida, visando à sua autonomia, independência, qualidade de vida e inclusão social (Comitê de Ajudas Técnicas, Cordel SEDH/PR, 2007, p. 26).

Há outras terminologias, como tecnologias de apoio e tecnologia de suporte, que podem ser divididas em várias categorias, como Auxílio para a vida diária; Comunicação suplementar e/ou alternativa; Acessórios para computador; Sistemas de controle de ambiente; Auxílio para mobilidade; Auxílio para deficientes visuais e auditivos. 


\section{Softwares especiais de acessibilidade}

O ingresso de uma aluna com necessidade educacional especial trouxe para a equipe envolvida no processo de ensino e aprendizagem o desafio da comunicação. Algumas questões inquietaram essa equipe. Como adaptar o material didático que era oferecido aos alunos no formato impresso para uma pessoa nessas condições? Quais seriam as reais necessidades dessa pessoa para cursar a disciplina Informática na Educação, considerando a existência de muitas imagens, vídeos e sites? Que tipo de jogo educativo poderia ser analisado para uma pessoa com deficiência visual? Quais os softwares disponíveis no sistema operacional Linux utilizados nos computadores dos Laboratórios de Informática da Fundação Cecierj?

Os arquivos de textos do material didático foram gravados de forma adaptada em mídias de CD-ROM por uma equipe especializada na produção de textos em áudio para pessoas com necessidades educacionais especiais. Foi oferecido o material impresso em Braille; contudo a preferência foi pelo material didático no formato de áudio.

Nessa experiência com a disciplina Informática na Educação a aluna recebeu as aulas em formato de áudio. A acessibilidade foi possível pelo uso do computador e da adaptação de todo o conteúdo da disciplina, incluindo a descrição de cada imagem.

Para tornar acessível o quadro teórico indicado na disciplina, foi realizada uma descrição adaptada do texto a ser lido por uma versão de teste do leitor de textos Speak Aloud. Ele não permite a leitura de arquivos em formato .pdf, .odt ou .doc, porém foi possível adaptar alguns arquivos para o formato .txt e a partir deste foi possível a leitura.

Entretanto, o programa tem alto custo e não é de domínio público. $\mathrm{O}$ alto custo dos programas privados e os conflitos que a maioria dos softwares apresenta em relação ao sistema operacional Linux fazem com que estudantes com necessidades educacionais especiais fiquem restritos no desempenho de suas atividades acadêmicas.
Em conversa por e-mail com a equipe da Plataforma Cederj, recebemos a recomendação de uso do software NonVisual Desktop Access (NVDA); é

um leitor de ecrã ou tela livre e código aberto para o sistema operacional Microsoft Windows. Conforme informa em seu site, fornece feedback via discurso sintético e Braille, que permite a cegos ou deficientes visuais acessar os computadores executando o Windows por não mais custo do que uma pessoa com visão. As principais características incluem suporte para mais de 20 idiomas e capacidade para executar inteiramente a partir de um drive USB sem instalação (JTEH, 2010, tradução nossa).

Esse software é de instalação fácil e rápida, não requer chaves ou senhas de acesso; faz a leitura de telas, textos, alguns links, e-mails... quase tudo em um site, apresentando ausência de leitura diante de imagens. Pode-se alterar a configuração de voz, velocidade, tipo, formato; reconhece outros formatos instalados no computador, entre outros.

Em seu tutorial, disponível no site http://www. nvda-project.org/wiki/Download, este software indica outros avanços em tecnologias assistivas de alto custo para os padrões de vida brasileiro.

A partir dos pressupostos teóricos apreendidos pelos alunos do curso de graduação em Pedagogia, a aluna teve como uma das questões de sua avaliação a distância (AD) a tarefa de conhecer sites criados para crianças e analisar como nossas crianças usam a internet em suas práticas cotidianas (na escola, em casa, na rua, nas lan houses). Considerando as limitações de recursos pedagógicos, a professora-tutora presencial e a aluna optaram por realizar a avaliação de dois jogos: Forcavox (jogo da forca Vox) e Memovox (jogo de memória Vox), já conhecidos pela aluna e disponibilizados pelo sistema operacional DOSVOX. O sistema possui 23 jogos, 17 utilitários, dentre eles o leitor de telas, e 11 aplicativos de acesso à rede internet, como correio eletrônico (Cartavox.txt), bate-papo sonoro pela internet (Papovox.txt) e acesso a home pages Intervox (Intervox.txt), entre outros, incluindo aplicativos multimídia. 
As primeiras análises sobre o Forcavox foram a percepção de uma leitura muito rápida, de metodologia de difícil compreensão, indicado para a crianças de 6 a 8 anos de idade em processo de alfabetização. Sobre o Memovox, foi observado que o jogo induz ao conhecimento do teclado; os exercícios de memória são oferecidos em diferentes níveis, de 1 ao 9; atende à faixa etária de 3 a 12 anos em processo de alfabetização. Ambos os jogos apresentam baixa possibilidade de interatividade, pois não permitem à criança criar, interagir com outras crianças; limita-se a seguir as regras $e$ as palavras sugeridas pelo sistema.

Foram experimentados os softwares DOSVOX, CPqD Leitor de Telas, Speak Aloud, NVDA. Para utilizar esses programas foi necessário instalar um módulo de acoplamento chamado SPCHAPI para usar o sintetizador de voz profissional do tipo Microsoft Speech API (SAPI3, SAPI4 e SAPI5). As análises sobre os softwares experimentados até $\mathrm{O}$ momento por esta tutoria presencial não pretendem esgotar o potencial de cada um deles, inclusive por considerar que todos esses projetos que resultaram na melhoria da qualidade de vida das pessoas com necessidades educacionais especiais encontram-se em permanente desenvolvimento. A ordem em que foram apresentados está diretamente relacionada com o conhecimento gradativo de cada um destes programas.

a) Sistema operacional DOSVOX: foi construído para microcomputadores da linha PC; ele se comunica com o usuário mediante síntese de voz, através de uma interface simples. Com ele é possível ler arquivos; alterar o volume do som; reler mensagens já ditas; fechar; editar textos; ler arquivo; configurar o DOSVOX; trabalhar com as seções do DOSVOX.INI, entre outros, conforme apresentação do manual básico do DOSVOX em sua versão 3.2.

b) Software $\mathrm{CPqD}$ Leitor de Telas: Este software, que tem sido utilizado nos telecentros do Parapan, permite a leitura automática de telas, arquivos textos e ações dos usuários. O aplicativo foi lançado com recursos do Funttel (Fundo para o Desenvolvimento Tecnológico das Telecomunicações) para ser utilizado em computadores de configuração simples. Para que todos os telecentros tivessem acesso, a ideia foi desenvolver também uma versão de software livre, conforme informações obtidas no portal da instituição.

c) Software Speak Aloud: Permite a leitura de textos em formato .doc, .odt, .pdf e a leitura de páginas da internet, a conversão de textos em arquivos de áudio no formato .wav ou MP3 e a gravação de outros tipos de arquivos de áudio disponibilizados em rádio, DVD, cassete ou LP para MP3, .wma e .ogg em tempo real. Oferece suporte a programação e detecção de atividade de voz.

d) Software NonVisual Desktop Access (NVDA): Este software permite a leitura de sites, dentre outros documentos, em mais de 20 idiomas; tem capacidade para executar a partir de um drive USB; dessa forma, não necessita de instalação. Com o simples passar do mouse sobre o texto, o ícone determina a leitura do programa, localizando a pessoa com deficiência visual em qualquer aplicativo ou site em que esteja navegando. As figuras e fotos são reconhecidas como links gráficos seguido da leitura do texto inicial do site, incluindo a legenda.

\section{Construção de blog}

O desenvolvimento de tecnologias que proporcionem a realização de determinadas tarefas no dia a dia de pessoas com necessidades educacionais especiais tem sido objeto de estudo de engenheiros, terapeutas e educadores, entre outros profissionais interessados na área. Entretanto, o envolvimento da pessoa com NEE numa proposta de investigação sobre os possíveis usos da tecnologia assistiva é condição sine qua non para que o projeto alcance o êxito desejado, pois somente aquele que se depara com um cotidiano repleto de barrei- 
ras arquitetônicas e atitudinais pode mensurar o quanto é difícil sobreviver num mundo pensado $e$ projetado para pessoas videntes.

Questões não faltavam, nem disposição em investigar sobre as possibilidades para que esse processo prosseguisse com êxito.

Outra barreira arquitetônica (e virtual?) eram os computadores com sistema operacional Linux, software livre, do laboratório de informática do Polo Cederj Angra dos Reis, incompatíveis com a maioria dos programas identificados. Por isso, nossa opção foi pela utilização dos hardwares (notebook $e$ mouse sem fio, pen drives e CD-ROMs) do pessoal da tutoria presencial.

Uma das atividades propostas na disciplina Informática na Educação foi a construção de um blog. Após a leitura do texto Uso do blog na prática pedagógica, de autoria e indicação da coordenação da disciplina, deparamo-nos com alguns obstáculos, como a leitura das imagens apresentadas no texto e dos links; diante destes, o software NVDA apresentava uma pausa que provocava na aluna a interrupção do pensamento sobre o assunto. Nesse momento, precisei intervir informando-a sobre a imagem, fazendo sua descrição e contexto ou mesmo lendo o link e aproveitando o momento para realizar as visitas sugeridas a eles. Mas outras questões se constituíram com a descrição de imagens, considerando que cada pessoa vê as fotografias $e$ as imagens a partir das influências vividas. Será que o método utilizado para a descrição das imagens contemplou o pleno entendimento do texto? Como utilizar a audiodescrição em ambientes virtuais de aprendizagem?

No momento de navegar nos blogs, a dificuldade em relação às imagens era a mesma; os vídeos também eram identificados pela leitura do título dos posts ou pelo texto - que em alguns foi possível identificar -; todavia, a frustração e a insatisfação eram notáveis e sempre ditas pela aluna. Da mesma forma aconteceu na navegação em vários outros sites, mesmo naqueles especializados em Educação Especial ou destinados a pessoas com deficiência visual. Os sites que possibilitavam na- vegação mais exitosa eram aqueles que apresentavam mais posts textuais.

Para a construção do blog da aluna, sugeri o Blogger, do Google, pois, além de ser gratuito, oferecia uma interface simples para o usuário primário, apesar de não apresentar estrutura acessível à pessoa com deficiência visual. Num contexto de sala de aula, em que as demais alunas construíam e conversavam sobre o que estavam pensando do projeto do blog, a ansiedade da aluna e das demais era percebida com grande entusiasmo pelo próprio grupo, que primeiramente tentava criar uma conta no site do Google, resgatar a conta criada para utilização do Orkut ou criar o próprio blog para logo em seguida nomeá-lo.

Para acessar a conta de e-mail e criação do blog no site do Google foi necessária a minha intervenção para a localização do cursor em lacunas específicas para preenchimento de dados pessoais pela aluna, leitura das palavras ou letras de segurança geradas pelo próprio site e a identificação da senha da aluna. Neste último item, o programa NVDA fazia, para qualquer caractere, a leitura da palavra "asterisco". A aluna concluiu que "sozinho, o deficiente não pode criar um e-mail ou se cadastrar em algum lugar (no ciberespaço)" (sic). Embora alguns sites ofereçam a leitura dessas palavras, letras ou códigos de segurança indicados pelo símbolo de um deficiente em cadeira de rodas, o som não é inteligível e o botão não é reconhecido pelo leitor de sites.

Com a utilização do programa NVDA, foi possível à aluna navegar pela Plataforma Cederj de forma autônoma, devido à sua estrutura fixa em três colunas, caixas de posts e à utilização de posts textuais. O mesmo foi percebido em outro momento mais à frente, com a construção do microblog Twitter, que apresentava uma estrutura fixa de duas colunas; posts em seu maior número textuais, links com fotos dos seguidores e seguidos também foram lidos pelo programa.

No momento da escolha do nome do blog, a aluna disse que fugiu o nome; no intervalo para a mediação com outra aluna que respondia sobre o 
nome do seu blog, orientei que o nome deveria fazer referência à proposta do blog; em seguida, a aluna $\mathrm{M}$ afirmou que desejava falar sobre acessibilidade. Recomendei que fechasse mais sua proposta de blog; assim, ela focou na acessibilidade do deficiente visual, logo sugerindo o nome "Navegando no escuro" (http://navegandonoescuro2010. blogspot.com/) e perguntando-me se seria possível. Ressaltei a ampla possibilidade de entendimento do nome do site.

A aluna ficou preocupada quando excluiu os seguidores do blog; quando clicou em outros links, em janela que estava minimizada; quando o sistema operacional iniciava outra atividade automática e sinalizava na tela, ou mesmo quando a conexão era interrompida e retornava; quando, ao tocar no sensor do notebook, diminuía o volume do som ou não lembrava a senha de alguma conta virtual; quando não conseguia visualizar seu blog ou outros na rede Cederj, devido ao bloqueio de acesso a alguns domínios pela instituição e era informada sobre o bloqueio com a mensagem "Acesso negado guardian".

A oportunidade de ter uma aluna com deficiência visual num curso de formação de professores abriu um canal de sensibilização no grupo de alunas de graduação provocado por uma atenção inicial às barreiras existentes naturalmente por um mundo que é pensado prioritariamente para as pessoas videntes. Contudo, a Plataforma Cederj apresenta alguns recursos que podem tornar a sua interface adaptável, como apresentação dos objetivos da WAI e W3C, disponibilidade para o usuário baixar o sistema operacional DOSVOX e o recurso de alteração de tamanho das letras.
Todavia, houve necessidade de buscar outros recursos que propiciassem a adaptação do ambiente virtual de aprendizagem à acessibilidade que pretende interagir na lógica comunicacional segundo a dinâmica "todos-todos" mencionada por Silva (2008), possibilitada pelo uso das interfaces nos AVAs.

\section{Conclusão}

$\mathrm{Na}$ confiança de que algumas contribuições foram significativas na implementação de uma forma de inclusão no ensino superior e considerando que

todo esse movimento e todas essas relações nos fazem perceber que não chegamos a saber bem onde e quando aprendemos, tanto quanto, muitas vezes, não sabemos quem ensinou ou quem aprendeu nesses diferentes processos cotidianos de criação de conhecimentos em redes (ALVES, 2010, p. 230).

A oportunidade de trabalhar com uma pedagoga em formação nos permitiu contribuir para a sensibilização do grupo de professores em formação, provocada pela atenção inicial às barreiras existentes naturalmente por um mundo que dá prioridade aos videntes. A Plataforma Cederj, em constante desenvolvimento, com o ingresso de $\mathrm{M}$ foi repensada a partir de alguns estudos e pressupostos, como a apresentação dos objetivos da WAI e W3C, o sistema operacional DOSVOX e outros.

Nesse perpétuo movimento de tornar acessível um ambiente virtual de aprendizagem no ensino superior na modalidade a distância, o repertório de possibilidades e expectativas foi ampliado pela possibilidade de adotar diversificadas técnicas de ajudas que favoreçam a realização de provas presenciais junto com toda a turma. 


\section{Referências bibliográficas}

ALVES, N. Educação e mídia: as tantas faces da professora 'usuária' dos artefatos tecnológicos. In: GARCIA, Regina Leite; ZACCUR, Edwiges (orgs.).Livro cotidiano e diferentes saberes. Rio de Janeiro: DP\&A, 2006.

BRASIL. Declaração de Salamanca e linha de ação sobre necessidades educativas especiais. Brasília: Corde, 1994.

BRASIL. Ministério da Educação. Plano Nacional de Educação. Brasília: Inep, 2001.

CANDAU, Vera Maria. A diferença na universidade ainda é mais um esbarrão do que um encontro. In: GARCIA, Regina Leite; ZACCUR, Edwiges (orgs.).Livro cotidiano e diferentes saberes. Rio de Janeiro: DP\&A, 2006.

CAPUTO, Stela Guedes. Fotografia e pesquisa em diálogo sobre o olhar e a construção do objeto. Teias, Rio de Janeiro, v. 1, p. 115-120, 2001.

COSTA, Alice Maria Figueira Reis da; SANTOS, Edméa. O desafio da acessibilidade na tutoria presencial na disciplina Informática na Educação no curso de Pedagogia à distância da UERJ/Cederj. In: II SEMINÁRIO WEB CURRÍCULO PUC - SP, 2010, São Paulo. Web Currículo PUC - SP. São Paulo: DTI - Núcleo de Mídias Digitais da PUC-SP, 2010. v. 1. p. 1-16.

FERRAÇO, C. E. Os sujeitos das escolas e a complexidade de seus fazeressaberes: fragmentos das redes tecidas em pesquisas com o cotidiano. In: GARCIA, Regina Leite; ZACCUR, Edwiges (orgs.). Livro cotidiano e diferentes saberes. Rio de Janeiro: DP\&A, 2006.

FREIRE, Paulo. Pedagogia do oprimido. $17^{\mathrm{a}}$ ed. Rio de Janeiro: Paz e Terra, 1987.

GALVÃO FILHO, T. A. ; DAMASCENO, Luciana Lopes. Tecnologias assistivas para autonomia do aluno com necessidades educacionais especiais. Revista Inclusão, Brasília, MEC, v. 2, n. 2, p. 25-32, 2006. Disponível em: http://portal.mec.gov.br/seesp/arquivos/pdf/revistainclusao2.pdf. Acesso em: 05 jan. 2009.

GARCIA, P. S. Novos rumos da educação no terceiro milênio. Folha de São Caetano, São Caetano do Sul, p. 2, 07 jan. 2001.

GÓES, Maria Cecília, A natureza social do desenvolvimento psicológico. Cadernos Cedes - Centro de Estudos Educação e Sociedade - Pensamento e Linguagem: estudos na perspectiva da psicologia soviética. $2^{a}$ ed., São Paulo: Papirus, 1991, p.17-24.

INSTITUTO BENJAMIN CONSTANT. O Sistema Braille no Brasil. Disponível em: http://www.ibc. gov.br/?itemid=99. Acesso em: 29 jul. 2010.

LEMOS, André; JOSGRILBERG, Fabio (org.). Comunicação e mobilidade: aspectos socioculturais das tecnologias móveis de comunicação no Brasil. Salvador: Ed. UFBA, 2009. 156 p. Disponível em: http://poscom.ufba.br/arquivos/livro_Comunicacao_Mobilidade_AndreLemos.pdf. Acesso em: 29 maio 2010.

MAFFESOLI, Michel. O conhecimento comum: introdução à Sociologia compreensiva. Trad. Aluízio Ramos Trinta. Porto Alegre: Sulina, 2010 (Coleção Imaginário Cotidiano) .

NIELSEN, J. Usability Engineering. Boston: Academic Press, 1993.

NÚCLEO DE COMPUTAÇÃO ELETRÔNICA - NCE/UFRJ - PROJETO DOSVOX. Disponível em: http://intervox.nce.ufrj.br/dosvox/download.htm. Acesso em: 20 fev. 10.

OLIVEIRA, Inês Barbosa; ALVES, Nilda (orgs.). Pesquisa nos/dos/com os cotidianos das escolas - sobre redes de saberes. Petrópolis: DP et Alii, 2008. Coleção Cotidiano e Pesquisa em Educação. 
PARENTE, A. Enredando o pensamento: redes de transformação e subjetividade. In: PARENTE, André (org.). Tramas da Rede. Porto Alegre: Sulina, 2004.

RODRIGUES, A. S.; SOUZA FILHO, G. L. Acessibilidade na internet para deficientes visuais. In: IV Workshop sobre Fatores Humanos em Sistemas Computacionais, 2001, Florianópolis. IV Workshop sobre Fatores Humanos em Sistemas Computacionais, 2001.

SANTAELLA, Lucia. Navegar no ciberespaço: o perfil cognitivo do leitor imersivo. São Paulo: Paulus, 2004 (Comunicação).

SANTAROSA, Lucila Maria Costi. Inclusão digital: espaço possível com necessidades educativas especiais. Revista do Centro de Educação, n. 20, 2002. Disponível em: http://coralx.ufsm.br/revce/ ceesp/2002/02/a1.htm. Acesso em: 17 out. 2008.

SANTAROSA, Lucila Maria Costi; CARNEIRO, Mara Lucia; PASSERINO, Liliana Maria; GELLER, Marlise; CONFORTO, Debora. Formação de professores: referenciais na construção da acessibilidade para ambientes virtuais de educação a distância. Revista Educação. Porto Alegre, ano XXX, n. 3 (63), p. 531-545, set./dez. 2007. Disponível em: http://revistaseletronicas.pucrs.br/ojs/index.php/faced/article/ viewFile/2748/2095. Acesso em: 27 fev. 2010.

SANTOS, Edméa Oliveira dos. O currículo e o digital: educação presencial e a distância Bahia. Dissertação (Mestrado em Educação). Universidade Federal da Bahia. 2007.

SANTOS, Edméa. A Informática na Educação antes e depois da web 2.0: relatos de uma docente-pesquisadora. In: LIMA Jr, Arnaud. (livro ainda sem título), Salvador, Ed. UNEB, 2009 (no prelo).

SIQUEIRA, Inajara Mills; SANTANA, Carla da Silva. Propostas de acessibilidade para a inclusão de pessoas com deficiências no ensino superior. Revista Brasileira de Educação Especial, Marília, v. 16, n. 1, apr. 2010. Disponível em: http://www.scielo.br/scielo.php?script=sci_arttext\&pid=S1413$-65382010000100010 \& \operatorname{lng}=$ en\&nrm =iso. Access em 30 ago. 2010.

USABILIDADE e AI. Usabilidade: um pouco da história e definição. Disponível em: http://webinsider.uol.com.br/2005/03/30/usabilidade-um-pouco-da-historia-e-definicao/ . Acesso em: 22 mar. 2010.

VYGOTSKY, L. S. Pensamento e Linguagem. Rio de Janeiro: Martins Fontes, 1998.

\section{Notas:}

O Sistema Braille, utilizado universalmente na leitura e na escrita por pessoas cegas, foi inventado na França por Louis Braille, um jovem cego, reconhecendo-se o ano de 1825 como o marco dessa importante conquista para a educação e a integração dos deficientes visuais na sociedade.

Sistema de cotas instituído pelas leis estaduais $n^{\circ} 4.151 / 03$, 5.074/07 e 5.346/08; fica reservado um percentual de $45 \%$ das vagas.

BORGES, José Antonio. DOSVOX - Uma nova realidade educacional para deficientes visuais. Disponível em: http://intervox.nce.ufrj.br/dosvox. Acesso em: 01 abr. 10.

INSTITUTO BENJAMIN CONSTANT. LÁZARO, Regina Célia Gouvêa. Deficiência visual. Disponível em: http://www.ibc.gov.br/Nucleus/index.php?itemid=93\#more. Acesso em: 01 abr. 10. http://www.ibc.gov.br/Nucleus/index.php?itemid=93\#more.

HARVEY, D. A condição pós-moderna. São Paulo: Loyola, 1989.

GIDDENS, A. As conseqüências da modernidade. São Paulo: Unesp, 1991.

Nova forma de mídia que utiliza o poder do computador para arquivar, recuperar, distribuir informa- 
ções na forma de figuras gráficas, texto, animação, áudio etc.; entre outros fatores ocorrem associações e interatividade; informações não sequenciais; hibridização da linguagem e sua capacidade de armazenar informações que se fragmentam.

Na revisão de SANTOS (2002), hoje denominamos de ciberespaço o complexo conjunto de relações sociotécnicas estruturadas na e pela infraestrutura das tecnologias digitais organizadas em rede pela interconexão mundial de computadores.

São comumente chamados de gadgets dispositivos eletrônicos portáteis, como PDAs, celulares, smartphones, leitores de mp3, entre outros. Wikipédia.

Disponível em: http://pt.wikipedia.org/wiki/Gadget.> Acesso em: 28 ago. 2010.

http://www.acessobrasil.org.br/index.php?itemid $=45$

http://www.w3.org/

http://www.w3.org/WAI/

http://portal.mj.gov.br/corde/

CENTRO DE PESQUISA E DESENVOLVIMENTO DA TELEBRÁS. O CPqD.

Disponível em: http://www.cpqd.com.br/2/1+o-cpqd.html. Acesso em: 05 mar. 10.

MERCADO, L. P. L. ; NASCIMENTO, E. F. ; SILVA, L. R. Uso do blog na prática pedagógica. In:

MERCADO, L. P. (org.). Práticas de formação de professores na educação a distância. Maceió:

EdUFAL, 2008, v. 1, p. 357-369.

SILVA, Marco. Cibercultura e educação: a comunicação na sala de aula presencial e online. Revista Famecos - Mídia, Cultura e Tecnologia. 2008. Disponível em: http://www.thefreelibrary. com/Cibercultura $+e+e d u c a c a o \% 3 \mathrm{~A}+\mathrm{a}+$ comunicacao + na + sala $+\mathrm{d} e+$ aula + presencial $+e .$. -a0197040684. Cibercultura e educação: a comunicação na sala de aula presencial e online. Acesso em: 28 jul. 